\title{
Principal Directions of Digital Transformation of Higher Education System in Sustainable Education
}

\author{
Elvir Akhmetshin ${ }^{1, *}$, Karine Barmuta ${ }^{2}$, Vladimir Vasilev $^{1}$, Hilary Okagbue ${ }^{1,3}$, and Ogochukwu \\ Ijezie $^{1,4}$ \\ ${ }^{1}$ Kazan Federal University, Elabuga Institute of KFU, Department of Economics and Management, \\ Kazanskaya Street, 89, 423604 Elabuga, Russia \\ ${ }^{2}$ Don State Technical University, Department of Economics and Management, Gagarin square, 1, \\ 344000 Rostov-on-don, Russia \\ ${ }^{3}$ Covenant University, Department of Mathematics, Ota, Nigeria \\ ${ }^{4}$ Bournemouth University, Faculty of Health and Social Sciences, Bournemouth, United Kingdom
}

\begin{abstract}
From the perspective of a systematic integrated approach, the article formulates the main directions of digital transformation of higher education system in sustainable education in all its components, taking into account the requirements of the modern digital economy as the leading trend in the country's innovative development model. The authors consider essential content of the digital economy as a vector of innovative trends focused on the training of specialists of a qualitatively different level, and present the results of the formation of the digital economy in the Personnel and Education direction in 2025. One of the essential components of the modern educational process is the electronic information and educational environment, which is considered as a system that includes innovative technology platforms as an indispensable element for the generation and processing of knowledge. The article explores the prospects for improving the Russian scientific and educational system based on innovative methods of education using neural network technologies, the need for a transition to online education with integrated systems of natural and artificial intelligence. The paper identifies obstacles that significantly hamper the sustainable development of online education, one of which is the lack of teachers of the new formation who can work in the digital environment. It also presents an analysis of the results of a comprehensive study to assess the readiness of higher education to the parameters of the digital economy, showing that most universities are at the initial stage of the informatization and automation processes, which proves the relevance of the materials presented.
\end{abstract}

*Corresponding author: elvir@mail.ru 


\section{Introduction}

The problem of digital transformation of higher education in the sustainable education has been one of the most actively discussed in the economic press in recent years [1-10]. At the same time, there are a number of issues having no unambiguous solution, which to some extent hinders the process of adapting higher education to the new reality (digitalization, Industry 4.0).

The solution to the problems associated with the training of qualified personnel for digital economy should undoubtedly be based on the reorganization of the educational process. In the next decade, significant changes in higher education should happen: the formation of a new middle class for the digital economy and the reorganization of educational processes based on the use of artificial intelligence technologies. Such technologies will radically change the content of the disciplines taught, as well as the form of presentation of material to students. Innovation will underlie the educational process, nurturing a generation ready to develop innovations and learn throughout lifetime. Flexibility, willingness to work on complex projects, borrowing best practices, including foreign ones, and monitoring trends in other professions and industries is to become the most important function of education.

\section{Methodology}

As the main goal of the study, the authors set the formation of principal directions of the Russian higher education system transformation, taking into account the requirements of the modern digital economy from the perspective of a systematic integrated approach.

In accordance with the goal, the object of study is the higher education system. The object of observation is the educational process. The subject of the study is the direction of transformation of higher education in accordance with the requirements of the digital economy.

The methodological and theoretical basis is the work of national scientists on the problem of the transformation of the higher education system in the digital economy, regulatory acts of the Russian Federation, decrees and reference mate-rials. The study uses the general scientific principles of the systematic approach, methods of comparative, logical, strategic analysis, causal methods.

\section{Discussion}

Consider, first of all, the essential content of the digital economy itself as a relatively new direction of the emerging innovative model of the country's development.

Until now, a unified definition of the phenomenon of the digital economy has not been developed, which can be explained by its novelty, the ambiguity of the internal content, leading to the use of such categories as "web-economy", "electronic economy", "Internet economy", "new economy" [1, 11-14].

The official definition of the category under study is given in Decree of the President of the Russian Federation dated May 9, 2017 No. 203 "On the Strategy for the Development of the Information Society in the Russian Federation for 2017-2023 [15]: "Digital economy is an economic activity in which the key pro-duction factor is data in digital form, the processing of large volumes and the use of analysis results which, compared with traditional forms of management, can significantly increase the efficiency of various types of production, technologies, equipment, storage sale, delivery of goods and services." 
A group of authors of the St. Petersburg State Polytechnic University proposed the author's definition of the digital economy, which meets the principles of complexity and systemacity. According to the well-founded opinion of the university scientists, the phenomenon of digital economy is that it is:

- a special type of economy characterized by such features as the active use of technologies for collecting, processing, converting and storing information in digital format [3];

- a complex multi-level system, including a combination of socio-economic and technoorganizational relations, formed and implemented on the basis of the wide use of digital information and telecommunication technologies [3];

- a multifunctional system allowing economic agents of the business environment to exchange various knowledge in the presence of technical, organizational, program elements that generally form the infrastructure of digital interaction [3].

Russia has adopted a special program, strategically important for the country, called Digital Economy, which outlines the main directions of digital transformation for government and municipal authorities, business entities, industries and sectors of the economy (Fig. 1).

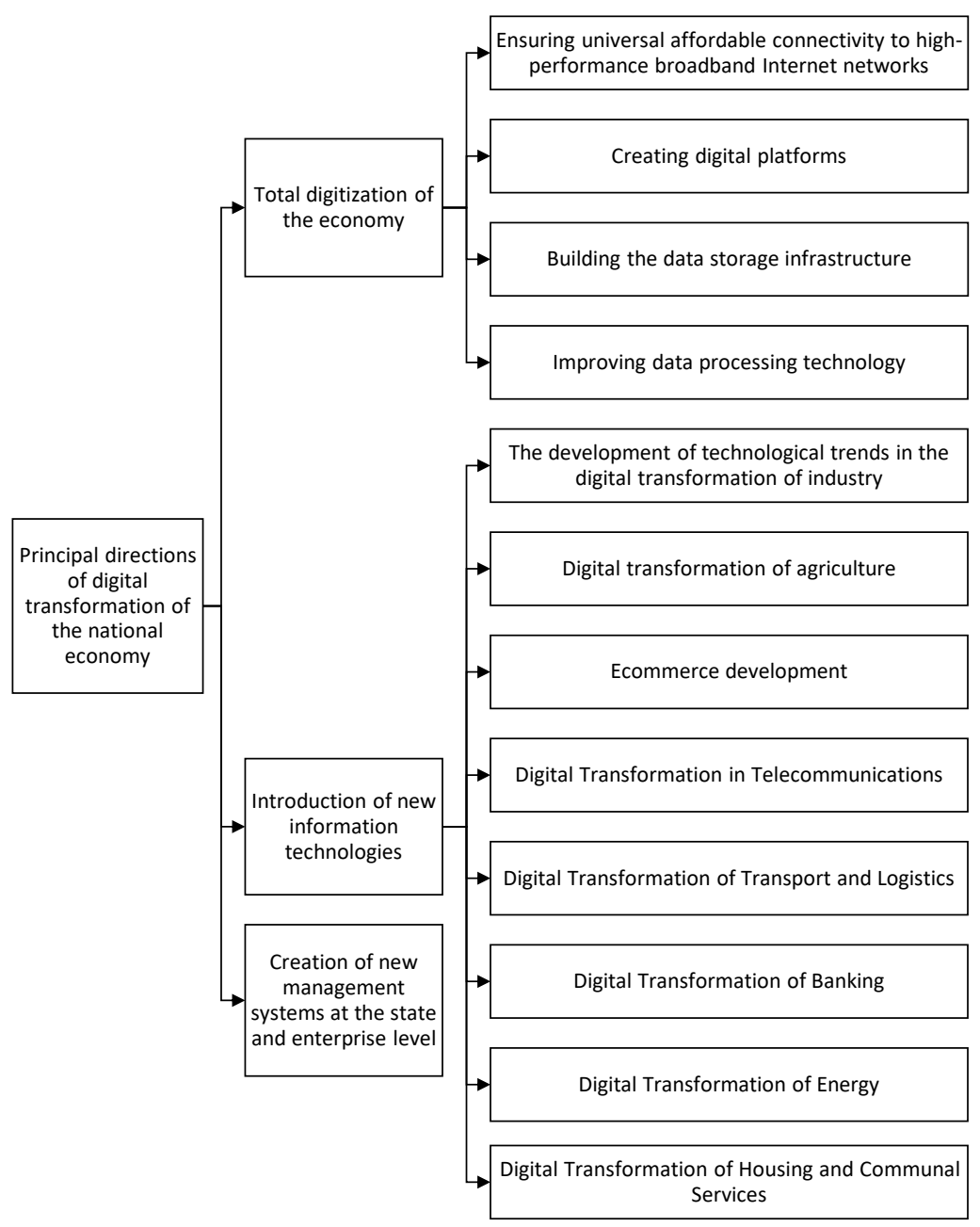

Fig. 1. Principal directions of digital transformation (compiled by the authors using sources $[12,15]$ ) 
It is the digital economy that sets innovative trends aimed at training special-ists of a qualitatively different level. Much will depend on how specific knowledge, skills and abilities gained in the learning process are consistent with the digital economy format, which itself is to undergo constant and fairly quick changes. [5].

The strategic function of modern higher education is to adequately support the digital economy with its inherent creative characteristics, innovative educational programs and research components. Otherwise, the entire range of educational tasks of the digital economy can go to the private sector, represented by both Russian and foreign providers of multifunctional digital educational platforms [16].

There are several principal directions of the higher education transformation in accordance with the requirements of the digital economy (Fig. 2).

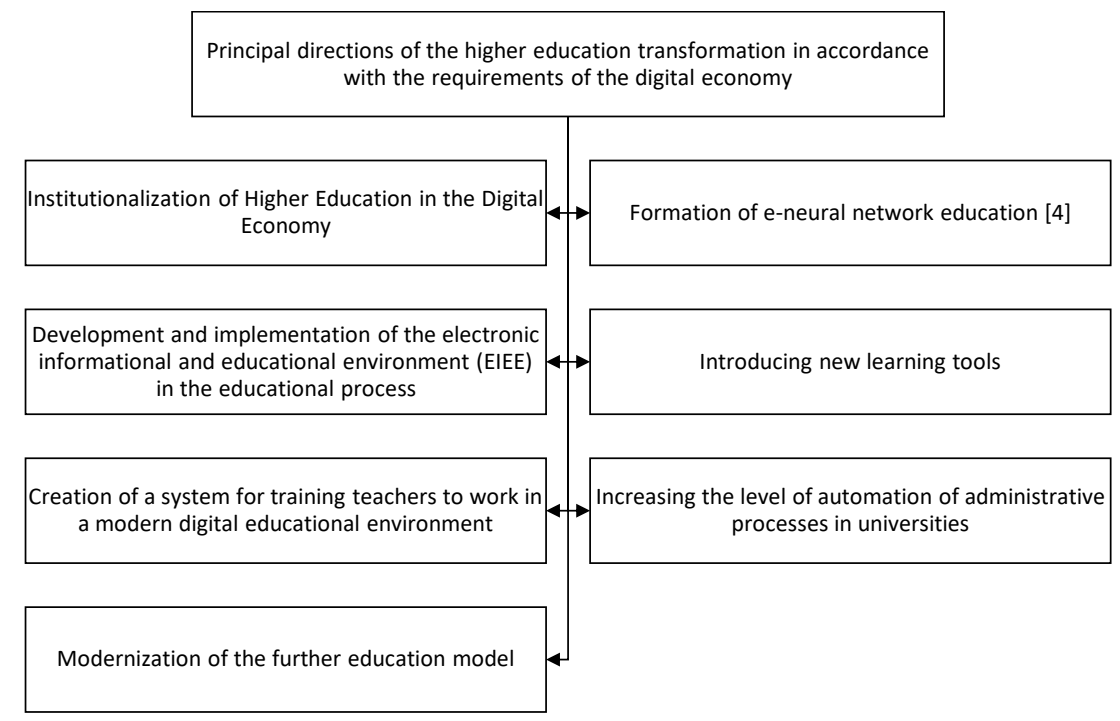

Fig. 2. Principal directions of the higher education transformation in accordance with the requirements of the digital economy (compiled by the authors)

The entry of higher education into digital technology inevitably requires the institutionalization of this creative process. Therefore, in addition to the legislative framework already developed in 2012-2018, for the functioning of higher education, it is necessary to supplement it with normative acts regulating:

- mechanisms of state participation in various areas of higher education in the specific conditions of digitalization;

- interaction between educational institutions and controlling state structures, operating in both conventional and digital formats [5].

First of all, the transformation of the higher education system in relation to the conditions of the digital economy should be based on the corresponding personnel component, for which a number of directions are provided in the general concept of the digital economy (Table 1) [17]. 
Table 1. The results of the digital economy formation in the Personnel and Education area in 2025

\begin{tabular}{|c|c|}
\hline \multicolumn{2}{|c|}{ Personnel and Education Area } \\
\hline Result & Features \\
\hline $\begin{array}{l}\text { A scientific and educational } \\
\text { environment will be formed in Russia, } \\
\text { which, by its principle, will be able to } \\
\text { take part in various international } \\
\text { alliances created for fundamental and } \\
\text { applied research }\end{array}$ & $\begin{array}{l}\text { An extensive network of collective use of information, digital } \\
\text { and technical and technological resources will begin to carry } \\
\text { out multifunctional activities. }\end{array}$ \\
\hline $\begin{array}{l}\text { Russia will significantly increase its } \\
\text { rating in terms of attractiveness for the } \\
\text { active work of IT-specialists }\end{array}$ & $\begin{array}{l}\text { The regulatory framework in conjunction with technological } \\
\text { and socio-economic platforms formed for the purpose of testing } \\
\text { the results of scientific research will be improved. Such } \\
\text { innovations will be subject to state support in the form of } \\
\text { various subsidies. }\end{array}$ \\
\hline $\begin{array}{l}\text { In the period until 2025, the issue of the } \\
\text { personnel component of the digital } \\
\text { economy will be completely resolved } \\
\text { and a balance between supply and } \\
\text { demand for the necessary specialties } \\
\text { will be achieved. }\end{array}$ & $\begin{array}{l}\text { The conditions necessary for the current and strategic } \\
\text { development of skills and competencies specific to the digital } \\
\text { economy will be formed. The organizational and economic } \\
\text { mechanism for training highly efficient specialists in various } \\
\text { fields of activity will operate subject to the principles of clarity } \\
\text { and effectiveness. The question of the reproductive aspect of } \\
\text { business activity of individuals whose age has exceeded } 50 \\
\text { years will be closed. All existing categories of citizens will } \\
\text { actively participate in the labor process, as well as receive high } \\
\text { wages, which will reduce unemployment and increase } \\
\text { quantitative demographic indicators of the country }\end{array}$ \\
\hline $\begin{array}{l}\text { Educational programs will include } \\
\text { competencies specific to the digital } \\
\text { economy, and their certification systems } \\
\text { will become variant }\end{array}$ & $\begin{array}{l}\text { The principles of education will be modernized and the main } \\
\text { ones will be such as a personalized approach, a dialectical } \\
\text { combination of educational and labor trends, active } \\
\text { involvement in the digitalization process will be carried out } \\
\text { starting from school }\end{array}$ \\
\hline $\begin{array}{l}\text { A comprehensive system will be } \\
\text { formed, with the feature of a reflection } \\
\text { of lifelong development of the citizen's } \\
\text { competencies }\end{array}$ & $\begin{array}{l}\text { The necessary data will be updated on the basis of } \\
\text { comprehensive certification and in the course of work }\end{array}$ \\
\hline
\end{tabular}

\section{Results}

There is a need to transform higher education, first of all, in accordance with the requirements of the modern labor market. According to various forecasts, over the next ten years such professions will appear that are currently even hard to imagine (Table 2) [18].

Table 2. Professions of the future

\begin{tabular}{|c|c|c|c|}
\hline \multicolumn{2}{|c|}{ Before 2025} & \multicolumn{2}{|r|}{ After 2025} \\
\hline Professions & Field of knowledge & Professions & Field of knowledge \\
\hline $\begin{array}{l}\text { Digital- } \\
\text { commentator } \\
\text { of culture }\end{array}$ & $\begin{array}{l}\text { PR and marketing, } \\
\text { business, history of arts }\end{array}$ & Space guide & $\begin{array}{l}\text { Socio-cultural service and } \\
\text { tourism, astronomy, } \\
\text { management, security }\end{array}$ \\
\hline $\begin{array}{l}\text { Roboethics } \\
\text { Lawyer }\end{array}$ & $\begin{array}{l}\text { Ethics, Communication, } \\
\text { Philosophy }\end{array}$ & $\begin{array}{l}\text { Environmental } \\
\text { Restoration } \\
\text { Engineer }\end{array}$ & $\begin{array}{l}\text { Biology, rehabilitation of } \\
\text { ecological systems }\end{array}$ \\
\hline $\begin{array}{l}\text { Virtual Habitat } \\
\text { Designer }\end{array}$ & $\begin{array}{l}\text { Editorial, architectural } \\
\text { design, game design, } \\
\text { psychology }\end{array}$ & $\begin{array}{l}\text { Constant Power } \\
\text { Developer }\end{array}$ & $\begin{array}{l}\text { Materials science (battery and } \\
\text { solar energy), chemistry, } \\
\text { energy }\end{array}$ \\
\hline
\end{tabular}


Table 2. Continued

\begin{tabular}{|l|l|l|l|}
\hline $\begin{array}{l}\text { Internet of } \\
\text { Things Data } \\
\text { Analyst }\end{array}$ & $\begin{array}{l}\text { Communications and } \\
\text { entrepreneurship, problem } \\
\text { solving, engineering, }\end{array}$ & $\begin{array}{l}\text { Personal data } \\
\text { curator }\end{array}$ & $\begin{array}{l}\text { Psychology, IT-technologies, } \\
\text { social networks }\end{array}$ \\
\hline $\begin{array}{l}\text { Freelance } \\
\text { biohacker }\end{array}$ & $\begin{array}{l}\text { Medical methodology, } \\
\text { biological sciences, data } \\
\text { analysis }\end{array}$ & $\begin{array}{l}\text { Human body } \\
\text { designer }\end{array}$ & $\begin{array}{l}\text { Materials science, } \\
\text { bioengineering, functional } \\
\text { modeling, medicine }\end{array}$ \\
\hline
\end{tabular}

Until 2025, they will include: a digital culture commentator, a roboethics lawyer, a virtual habitat designer, an Internet of Things data analyst, and a freelance biohacker. After 2025 , creative professions will appear such as a space guide, environmental restoration engineer, constant food developer, personal data curator, human body designer [18].

According to analysts, such intellectual professions as a librarian, archivist, travel agent and others will disappear from the labor market, which can lead to structural unemployment (Fig. 3).

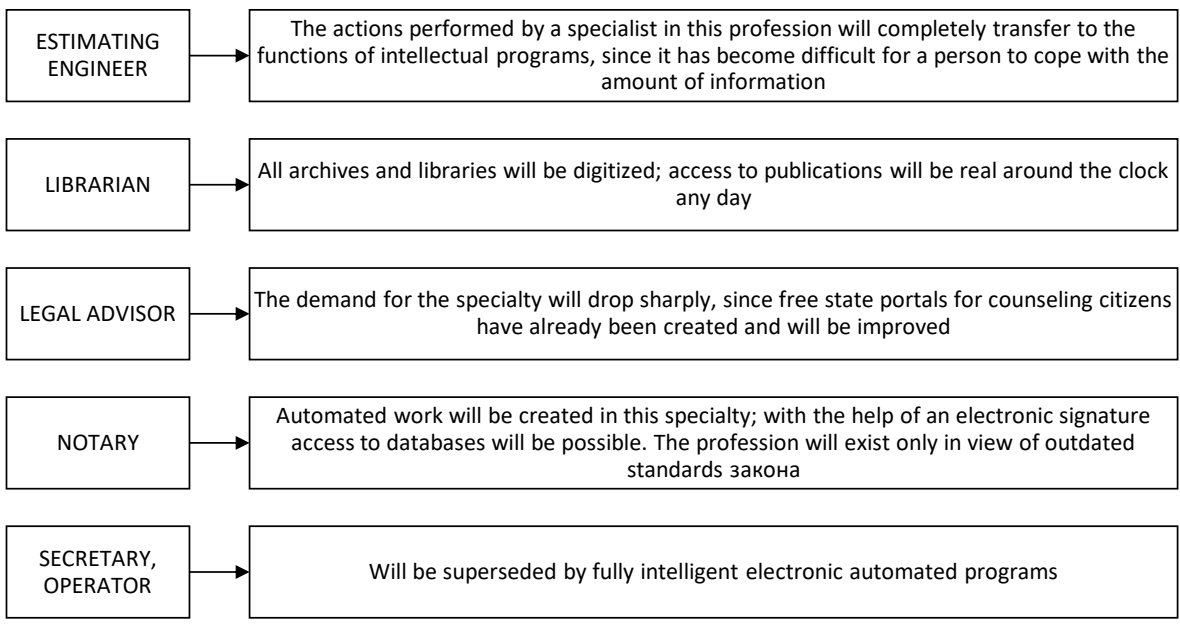

And such professions as: REALTOR, ANALYTIC, LOGIST, DISPATCHER, BANK OPERATIONIST, COPYWRITER, NETWORK ENGINEER, DRILLER, TRAVEL AGENT

Fig. 3. Retired professions [1]

The electronic information and educational environment (EIEE) is one of the essential components of the modern multifarious educational process. EIEE, considered as a system, includes the following interconnected elements: information and educational resources in electronic format, telecommunication technologies and the corresponding technological means. EIEE should include as a mandatory element innovative technology platforms designed to generate and process an array of knowledge that will allow all participants in the educational process to carry out the necessary interaction through the use of various communication channels [19].

EIEE makes it possible to effectively monitor the learning work of each student. The use of multimedia teaching materials to some extent relieves teachers of the responsibility for the "delivery" of educational content and creates the opportunity to focus on organizational, pedagogical and educational work.

Achieving the necessary pedagogical goals based on the use of EIEE is effected by:

- the formation of skills of research activity by modeling the work of scientific laboratories; 
- the formation of skills to obtain the necessary information from various sources and process it using modern computer technologies [20];

- the organization of various joint both educational and research work of students and faculty;

- systematic exchange of information on joint projects;

- the formation of students' communication skills and communication culture;

- organization of operational consulting;

- humanitarian development of students in various programs.

One of the important and critical conditions for the successful digitalization of higher education is the preparedness of the teachers themselves to work in new conditions. In this regard, it is necessary to improve their qualifications in terms of the formation of basic information competencies: work with text editors and spreadsheets, e-mail, Skype, preparation of presentations, computer testing of students [17]. It seems appropriate to restructure the Road Map of the Digital Economy of the Russian Federation Program. To this end, in the project "Personnel for the Digital Economy" it is advisable to identify priority areas for retraining faculty in the practical use of digital technologies and highlight the basic universities for such work with the organization of the "Schools of Digitalization" based on them.

The dynamics of the development of modern economic processes imposes requirements on employees in terms of new knowledge and skills, competencies that can be obtained in the process of further education. In this regard, the objective need is to modernize the system of additional education in the following areas: development of a wider list of programs; the increase in training programs implemented through online platforms; wide development of online forms of education; implementation of active cooperation with professional communities. The implementation of these measures will contribute to building an additional education system to meet the requirements of modern business and its digital components [21].

With the development of the new generation of the global computer network "Neuronet", prospects for improving the Russian scientific and educational system have appeared, in which traditional methods of education are replaced by innovative, based on the use of neural network technologies.

New forms of learning through the neural network will be developed; virtual research, modeling; computer-neural networks, hybrid, socio-neuromorphic research communities, groups, laboratories; the massive use of neuro helmets to use neurovirtual reality (virtual spaces, libraries, databases) for education and advanced training [4].

The most preferred segments of the products and methods of neuro-education will be such as online education, mass open distance learning courses [22, 23], combined training, additional education, as well as integrated systems of natural and artificial intellects.

One of the leading trends in modern higher education is the transition from the traditional model of education to online education. However, there are still a number of obstacles that significantly hamper its sustainable development. These include: lack of proper legislative regulation of online education; the lack of introduction of distance technologies in the educational process, which is associated both with the low level of development of innovative infrastructure and the lack of teachers of the new formation who are able to work in a digital environment; low percentage of students who are able to successfully complete their education online. In addition, according to the results of opinion polls, students themselves do not consider digital education as a full-fledged one. The correction of the current situation requires the creation of adaptive mechanisms to bring the educational system closer to the constantly changing needs of the labor market, and to individualize educational paths [24]. The training of teachers of the new formation who are able to work effectively in a digital environment is also required. A modern teacher must 
simultaneously combine three different types of competencies: he must be a specialist in the subject area (preferably with practical experience), he must be a teacher who who has mastered modern educational technologies, and he must possess the necessary digital competencies (i.e. be an advanced user of modern information systems). It should also be noted that the process of teaching through online platforms itself requires a number of extremely specific skills, such as, for example, the ability to be natural on camera, which, obviously, differs from the ability to deliver a lecture in a conventional lecture hall [25].

The online education market in Russia is still in its infancy. At the same time, in a number of countries it is characterized by intensive growth. For example, in the Chinese model of education, it is not classical university distance education that predominates, but various online courses designed for retraining and advanced training of personnel.

Among European countries, the leader in distance education is the United Kingdom. For example, the University of Liverpool as one of the leading universities in the world offers more than 40 programs in various sectors of the economy.

According to most experts in the field of online education, it should be actively developed in the segment of further education and advanced training and direct the necessary investments into it.

Solving the complex of digitalization problems of higher education is impossible without the introduction of new teaching aids in the educational process.

In the situation of a significant acceleration of the pace of scientific and technological progress and the wide introduction of various communication tools and technologies in the educational process, there is a real opportunity to achieve a higher level of information support for the educational process. Which, undoubtedly, will have a positive effect in the context of both general cultural and professional training [26].

The following are used as technical teaching aids in higher education: traditional analog technical means; digital technical means; computer multimedia - means of recording, processing and reproduction of sound; telecommunications facilities; means of access to information resources.

The advantages of an electronic textbook compared to its traditional version are as follows $[27,28]$ :

- the ability to illustrate dynamic processes;

- the presence of a variety of models in the photographs and their detailed characteristics in the tables;

- the ability to make the necessary changes to the material.

The essential thing is that the introduction of innovations in the educational process in the form of various technical means and information technologies should have an appropriate justification and function as a complementary and non-replacing factor in the educational process.

\section{Conclusion}

Of significant interest are the results of a study related to assessing the readiness of Russian higher education to work in a digital economy. For its implementation, the World Bank methodology was used, which was adapted to the Russian peculiarities of higher education, and discussed in the Analytical Center under the Government of the Russian Federation. In the methodology in question, the readiness of the country's higher education to the digital economy was assessed by the following groups of indicators [14]:

- the level of information technology used in the educational process;

- the level of training of teachers in the use of information educational technologies;

- infrastructure informatization support of educational activities;

- institutional support of the digital components of the educational process. 
The analysis of the results of the comprehensive study to assess the readiness of higher education to the parameters of the digital economy has led to the conclusion that only a small part of the universities has passed the informatization and automation stage, most of the universities being still at the initial stage of these processes.

Consequently, further transformation of the Russian system of higher education in all areas of its educational activities is necessary, taking into account the requirements of the modern digital economy, which will let it rank high in the world.

\section{Acknowledgements}

The work is performed according to the Russian Government Program of Competitive Growth of Kazan Federal University.

\section{References}

1. R. K. Asanov, Social and economic sciences and humanities, 15, 143 (2016)

2. 10 professions of the future: What will happen in 2025 and later, http://www.ucheba.ru/

3. A.V. Babkin, D.D. Burkaltseva, D.G. Kosten, Yu. N. Vorobyov, Scientific and technical statements of SPbSPU. Economics, 10(3), 9 (2017)

4. S.A. Dyatlov, E-neuronetwork education in the digital age: theory and practice. Innovation, 8(226), 91 (2017)

5. M. I. Irodov, Yu. V. Korechkov, Bulletin of Eurasian Science, 10(1), 13 (2018)

6. N. Sh. Kozlova, Bulletin of Maykop State Techno-logical University, 1(40), 83 (2019)

7. N.V. Kuznetsov, E-Management, 2(1), 19 (2019)

8. G. N. Andreeva, S.V. Badalyants, T.G. Bogatyreva, The development of the digital economy in Russia as a key factor in economic growth and improving the quality of life of the population: monograph (2018)

9. R. M. Safuanov, M. Yu. Lekhmus, E. A. Kolchanov, Bulletin of USTU. Science, education, economics, Economics series, 2(28), 116 (2019)

10. V.A. Semenikhina, Bulletin of the Volgograd Institute of Business, 2(47), 180 (2019)

11. B.N. Panshin, Science and innovation, 3(157), 17 (2016)

12. E.I. Parkhomenko, In: Problems and prospects for the development of education: materials of II International. scientific conf., 151 (2012)

13. S. Ziyadin, A. Serikbek, Lecture Notes in Networks and Systems, 84, 290 (2020)

14. A.G. Polyakova, M.P. Loginov, A.I. Serebrennikova, E.I. Thalassinos, International Journal of Economics and Business Administration, 7(1), 130 (2019)

15. Decree of the President of the Russian Federation of May 9, 2017 No. 203 "On the strategy for the development of the information society in the Russian Federation for 2017-2030." ATP "ConsultantPlus"

16. N.A. Dneprovskaya, Statistics and Economics, 15(4), 16 (2018)

17. A.E. Belolipetskaya, Management Issues, 5(48), 120 (2017)

18. Russia: trends and development prospects. Yearbook, 13, 1, RAS. INION. Sep. Scientific cooperation (2018)

19. V. M. Dubov, E. A. Kubryakov, V. V. Malev, Electronic timetable as an element of the educational information environment of a university. New Science: Strategies and Development Vectors, 118(2), 47(2016) 
20. E. M. Bazanova, Bulletin of Moscow State Linguistic University, 14(674), 24 (2013)

21. S. Ziyadin, S. Suieubayeva, A. Utegenova, Digital transformation in business. Lecture Notes in Networks and Systems, 84, 408 (2020)

22. O. Korableva, T. Durand, O. Kalimullina, \& I. Stepanova, Usability testing of MOOC: Identifying user interface problems. Paper presented at the ICEIS 2019 - Proceedings of the 21st International Conference on Enterprise Information Systems, 2, 468, (2019).

23. O. Korableva, T. Durand, O. Kalimullina, \& I. Stepanova, Studying user satisfaction with the MOOC platform interfaces using the example of coursera and open education platforms. Paper presented at the ACM International Conference Proceeding Series, 26, (2019)

24. L. Petrova, E. Ivanova, A. Plotnikova, M. Melnikov, \& V. Antonov, International Journal of Engineering and Advanced Technology, 9(1), 7517 (2019)

25. M. S. Kudlaev, Young scientist, 31, 3 (2018)

26. L. B. Beloglazova, O. V. Bondareva, Bulletin of the Peoples' Friendship University of Russia. Series: Education Informatization, 2, 35 (2015)

27. G. A. Mavlyutova, Economic safety and quality, 3(32), 5 (2018)

28. B. Kh. Shodyrova, E. K. Avilova, Young scientist, 20(124), 223 (2016) 